\title{
Mulheres em movimento: a presença feminina nos primórdios do esporte na cidade do Rio de Janeiro (até 1910)
}

\author{
Women in movement: the feminine presence in the \\ very beginnings of sports in the city of Rio de Janeiro
}

Victor Andrade de Melo*

\section{RESUMO}

Este artigo tem por objetivo discutir a presença feminina nos primórdios do esporte na cidade do Rio de Janeiro (até 1910). Nesse sentido, utilizamos como fontes jornais e revistas do período, bem como livros de memorialistas. $\mathrm{O}$ intuito é apresentar um panorama do envolvimento das mulheres com os mais diferentes esportes, em diversos momentos históricos, desempenhando distintos papéis. Ao captar as peculiaridades de cada uma dessas ocorrências, podemos ter um perfil das tensões e enfrentamentos encarados pelas mulheres no período estudado. Ao final, concluímos que se o aumento da presença feminina de alguma forma atendeu a alguns interesses masculinos, também foi fruto das distensões sociais e resultado de suas reivindicações, devendo também ser considerado como uma conquista.

Palavras-chave: esporte; mulheres; gênero.

\section{ABSTRACT}

This article discusses the presence of women in the early days of sport in the city of Rio de Janeiro (until 1910). To this end, newspapers and magazines published in the city at the time were researched, as well as books of memoirs. The goal is to present an oversight of the involvement of women in different sports, at various historical moments, performing distinctive roles. Looking at the peculiarities of each of those occurrences, we can trace a profile of the tensions and confrontations women faced at the time. In conclusion, we noted that if the increase of the feminine presence met, in a way, masculine interests, it was also a result of social expansion and their demands for their rights, and it should also be seen as a conquest. Keywords: sport; women; gender.

\footnotetext{
* Programa de Pós-Graduacão em História Comparada - Instituto de Filosofia e Ciências Sociais Universidade Federal do Rio de Janeiro (UFRJ), Largo de São Francisco de Paula, 10, sala 311, Centro. 20051-070 Rio de Janeiro - RJ - Brasil. victor.a.melo@uol.com.br. Coordenador do "Sport": Laboratório de História do Esporte e do Lazer (www.lazer.eefd.ufrj.br/sport).
} 
Julho de 2007. O país assiste a algo que há pouco tempo pareceria inusitado: a seleção brasileira feminina de futebol, que vinha encantando o público por suas belas performances, conquista a medalha de ouro nos Jogos Panamericanos do Rio de Janeiro, saudada por uma torcida entusiasmada que lotara o Estádio Mário Filho (Maracanã). A imprensa, no decorrer da campanha vitoriosa, exalta a qualidade das jogadoras, divulga suas histórias de superação e cobra maiores apoios e investimentos para o esporte feminino.

Também não foram incomuns as comparações com os homens, algo enfatizado pelo fato de que, na ocasião, as seleções masculinas (tanto a principal quanto a que participava dos Jogos Pan-americanos) não apresentavam bom desempenho. Não raramente público e imprensa clamaram: "Marta na seleção!”.

Marta é a melhor jogadora do selecionado e uma das melhores do mundo; joga na Europa porque no Brasil não há estrutura para que por aqui permaneça. No nosso país, o reconhecimento de seu sucesso se dá quando é comparada à equipe masculina: o termo 'seleção', assim como 'futebol', sempre esteve relacionado ao âmbito dos homens. Alguns meses após a conquista histórica, o futebol feminino nacional continua sem uma estruturação mínima.

Essa ocorrência recente permite-nos observar algo sobre as imprecisões e tensões que sempre existiram no que se refere à presença de mulheres no campo esportivo brasileiro. Ainda que nos últimos anos se possam perceber avanços significativos, há que se reconhecer que, em geral, elas ainda têm que lidar com maiores dificuldades (se compararmos com o esporte masculino), menor valorização (expressa até nos salários e premiações) e mesmo com a persistência de preconceitos e estereótipos.

O grande interesse dessa discussão para que reflitamos sobre a construção sociocultural brasileira é que as peculiaridades do envolvimento de mulheres em um espaço que originalmente foi majoritariamente concebido como território masculino, em grande medida refletem as lutas e reivindicações femininas por reconhecimento de sua possibilidade ampla de participação social. Nessa trajetória podemos perceber as tensões constantes entre 'adequação' e 'subversão', o que ocasionou, no mínimo, a ampliação dos papéis concebidos para homens e mulheres na sociedade brasileira.

Como, quando e por que se deu o envolvimento feminino com o campo esportivo no Brasil? Quais sentidos e significados estariam por trás disso? Como a prática esportiva ajudou a consolidar e/ou ampliar e modificar comportamentos considerados adequados para homens e mulheres? Este artigo, 
tendo em vista tais questões, tem por objetivo discutir a presença feminina nos primórdios do esporte no Rio de Janeiro (até 1910).

Esta cidade foi escolhida por ter sido a capital do país no período estudado, por sua importância como centro dos acontecimentos nacionais, bem como por ter sediado, no Brasil, os primeiros momentos da organização do esporte em seu sentido moderno, abrigando os pioneiros clubes estritamente esportivos, responsáveis por inicialmente estruturar e fazer desdobrar todas as dimensões que marcam essa importante manifestação cultural. ${ }^{1}$

Para alcance do objetivo, utilizamos como fontes jornais (como O Paiz e o Jornal do Brasil, entre outros) e revistas (como O Malho, a Revista da Semana e a Fon Fon, entre outras) publicadas na cidade no período estudado, bem como livros de memorialistas. Um importante material foi o periódico $\mathrm{A} C \mathrm{Ca}$ noagem, dedicado especificamente ao remo, lançado em 1903 pela Federação Brasileira de Sociedades de Remo. Essa publicação expressa o ponto de vista dos próprios clubes de regatas, a maneira como eles desejavam ser vistos tanto pelo público em geral quanto pelos envolvidos com outras manifestações esportivas.

O intuito deste artigo é apresentar um panorama do envolvimento feminino com os mais diferentes esportes, em diversos momentos históricos, desempenhando distintos papéis. Ao captar as peculiaridades de cada uma dessas ocorrências, podemos ter um perfil das tensões e enfrentamentos encarados pelas mulheres no período estudado.

\section{AS MULHERES E O TURFE: PRIMEIROS MOMENTOS}

O turfe foi o primeiro esporte, no sentido adotado neste artigo, a se organizar na cidade do Rio de Janeiro. Nas décadas de 1810 a 1840 pode-se identificar a promoção de algumas corridas de cavalos, normalmente realizadas na Praia de Botafogo, já contando com alguma afluência de público e presença de importantes personalidades da política nacional. Mas o marco definitivo de sua estruturação é a criação do Club de Corridas, em 1849.

Depois de um início eivado de dificuldades, fruto tanto do desconhecimento do público, tão importante para a manutenção da atividade, quanto da inexperiência dos organizadores, membros das elites econômicas, o turfe vai se consolidando como uma alternativa de diversão: era popular, atraindo pessoas de diferentes estratos sociais, mas também, para os dirigentes e sócios dos clubes, estava ligado à busca de elementos de status e distinção, fun- 
cionando até mesmo como estratégia direta e indireta de negócios. Na década final do século XIX, já existiam na cidade cinco hipódromos funcionando simultaneamente, envolvendo grande parte da população, gerando um mercado ao seu redor; as corridas de cavalos eram um assunto constantemente abordado pela imprensa.

Como teriam as mulheres se envolvido com o turfe? Que significado denota tal participação? Até meados do século XIX, devemos lembrar, não lhes era permitida grande movimentação, principalmente àquelas pertencentes às elites. Criadas pelos pais para serem boas donas de casa, em geral, no máximo, lhes era franqueado o acesso às primeiras letras, já que as habilidades ligadas ao lar (corte, costura etc.) é que eram consideradas relevantes. Os casamentos eram na sua maioria de conveniência, determinados pela família, envolvendo estratégias para o fortalecimento e/ou reorientação dos negócios.

Von Leithold, um viajante de origem prussiana, observa sobre a presença da mulher na sociedade carioca no primeiro quartel do século XIX: "A passear são raramente vistas, pelo menos nunca encontrei senhora de alguma importância assim ocupada e, como muitas casas têm suas capelas ou oratórios em que se reza missa nos dias de guarda, é uma exceção que se deixem ver a pé pelas ruas". ${ }^{2}$

A partir de meados do século XIX esse quadro começa paulatinamente a se modificar. Junto com os ventos de inovações vindos da Europa, chegavam também os ecos das reivindicações femininas e um novo modelo de mulher, mais presente na vida social. ${ }^{3}$ Essa mudança foi lenta e diferenciada entre os estratos sociais.

O turfe foi uma das válvulas de participação social feminina, já que era considerado de caráter aristocrático e familiar. Os hipódromos logo se constituíram em locais adequados para ver e ser visto. Nas instalações e eventos turfísticos as mulheres estavam sempre presentes, acompanhando seus pais ou maridos e, para as que podiam, desfilando seus vestidos de última moda.

Eduardo Pacheco ${ }^{4}$ comenta tal fato de forma irônica, lembrando que havia até mesmo uma moda específica nos hipódromos: chapéus, jóias e fazendas que faziam menção ao esporte: "Eram leques e abanicos de todas as cores, tamanhos e feitios; figuras grotescas penduradas aqui e acolá”. Olavo Bilac também dá seu olhar sobre esse aspecto:

Era uma coisa assombrosa! Todo mundo falava a gíria do desporto. Todos os homens usavam na gravata o alfinete clássico da ferradura. As fazendas, em que 
as senhoras cortavam os seus vestidos, tinham estampagens de chicotes, de loros, de casquetes de jóquei. ${ }^{5}$

Não se pode desconsiderar que a presença feminina nos prados era também concebida como mais uma forma de apresentar as mulheres à "nata da sociedade", tornando-as conhecidas de algum "bom partido", predispondolas a um bom matrimônio. Para as solteiras era mesmo uma possibilidade de flertar, algo que afrontava a tradicional estrutura social.

São inegáveis as novas dinâmicas ocasionadas por esse encontro dos dois sexos nas arquibancadas. Vale a pena citar "História de um soneto", ${ }^{6}$ de Arthur Azevedo, que narra como um rapaz se apaixona por uma das mais belas mulheres da cidade exatamente em um evento de turfe:

Ludgero encontrou-a um dia no Jockey Club, e aconteceu-lhe o mesmo que a todos os rapazes de seu gênero: enamorou-se dela. Dali por diante não perdia corrida de cavalos em que Laura Rosa estivesse, e, ou fosse que realmente os olhos da formosa dama lhe prometessem mais do que deviam, ou fosse natural filáucia de namorado jovem, ele considerou-se autorizado a empregar algumas diligências, a fim de que os seus amores saíssem do período ingrato do platonismo, e entrassem numa situação mais positiva.

A despeito do seu envolvimento como público nos hipódromos, não foi possível identificar a presença de mulheres nas diretorias dos clubes ou entre os organizadores de competições. Na verdade, os 'clubs', uma nova instituição no cenário carioca do século XIX, de clara inspiração européia, eram basicamente uma entidade masculina nos seus princípios, ainda que contemplassem a possibilidade de participação feminina em algumas atividades. ${ }^{7}$ No caso do turfe, os regulamentos e notícias nos jornais sempre destacavam os 'cavalheiros' como dirigentes, nunca as 'damas'.

Esse aspecto poderia ser lido como expressão de que às mulheres era resguardado um papel secundário: meras assistentes, constantemente exaltadas por 'embelezarem' e demonstrarem o quanto 'familiar' era o espetáculo, ajudando a compor uma performance pública masculina. Parece inadequado tal entendimento, ainda que não esteja completamente equivocado. Há que se considerar que naquele cenário as mulheres ocupavam um espaço de importância na construção de um novo imaginário. Se pensarmos nos salões, que ocupavam um espaço intermediário entre os clubes (públicos) e as diversões 
familiares (privadas), reforçaremos nossa compreensão acerca de seu relevante papel no contexto social do instante.

Além disso, não se pode negar que isso trouxe novas possibilidades de vivências e de exposição pública que semearam e/ou ajudaram a prosperar novos comportamentos. Por exemplo, focalizando um fato específico do turfe, vale destacar que houve até mesmo a realização de algumas corridas de cavalos com jóqueis mulheres, como a anunciada pelo jornal $O$ Globo de 25 de outubro de 1875 (provas no Prado Fluminense).

No Derby Clube, que, dirigido por Paulo de Frontin, buscava construir sentidos diferenciados para o esporte (cujo maior exemplo de tradição era o Jóquei Clube), ${ }^{8}$ foram ainda mais freqüentes as provas femininas. Uma ocorrência interessante, referente a outra cidade, mas digna de nota, foi o fato de Maria Domitila de Aguiar e Castro, neta da Marquesa de Santos, ter vencido o terceiro páreo das provas inaugurais do Jóquei Clube de São Paulo (1876).

Mulheres conduzindo cavalos em provas públicas de turfe é algo que deve ser encarado como uma exceção para a época: era visto como uma curiosidade, uma excentricidade. Há, contudo, uma ressalva a ser feita, importante para que melhor consideremos o que significava essa restrição às mulheres no papel de jóqueis.

Mesmo para os homens das elites essa era uma posição considerada menor. Ainda persistiam na cidade dúvidas sobre a natureza das atividades físicas, encaradas como similares às manuais. Os homens deveriam cuidar do intelecto e dos negócios, não do corpo. Os responsáveis pela condução dos cavalos normalmente eram membros das camadas populares ou estrangeiros contratados; só excepcionalmente alguém das "melhores famílias" tomava parte nas provas, em festivais beneficentes ou datas festivas.

Portanto, as restrições não eram exclusivas às mulheres, ainda que certamente sobre elas pairassem maiores desconfianças, em função da questão do pudor. Somente com o decorrer do desenvolvimento do campo esportivo, inclusive com o surgimento de outros esportes, é que a presença de mulheres como competidoras passou a ser mais freqüente, conforme veremos a seguir. De qualquer maneira, é importante registrar que desde o início encontramos a possibilidade de envolvimento feminino no âmbito da prática esportiva.

AS MULHERES, OS BANHOS DE MAR E O REMO

Como vimos introdutoriamente no item anterior, desde a metade do século XIX, ainda mais claramente na transição para o século XX, identificamse claras mudanças nos papéis femininos. Se ainda persistiam muitas das con- 
siderações e constrangimentos, já se percebe uma maior presença das mulheres no espaço público, conseqüência das próprias modificações culturais em curso na cidade e dos primórdios de uma tomada de posição pela igualdade de condições.

Ainda que embrionárias, tais discussões traziam à luz questões constantemente debatidas na Europa. A "imprensa feminista” da época, representada por jornais e revistas como "O Quinze de Novembro do Sexo Feminino" (de 1889), "A Família” (de 1897) e "A Mensageira" (de 1897), fazia de alguma forma circular temas como o sufrágio universal, a liberdade sexual e o acesso da mulher à educação. ${ }^{9}$

Esse quadro também tem relação com a nova dinâmica social observável no fin de siècle do Rio de Janeiro. O processo de urbanização e o desenvolvimento de um melhor sistema de transporte (com o surgimento do bonde, primeiro a tração animal e depois elétrico) 'convidavam' as mulheres à rua, aumentavam sua possibilidade de mobilidade, criavam contrapontos à tradicional idéia de confinamento doméstico. A presença feminina é cada vez mais constante nas competições esportivas, no teatro, no cinema, nos parques públicos.

Algumas influências, como a do higienismo, de alguma forma também contribuem para essa movimentação, como bem percebe Eugene Weber: transforma-se paulatinamente o ideal de feminilidade "da opulência e palidez de meados do século para um tipo mais esbelto e mais saudável de beleza, menos gorducho, mais esportivo" (Weber, 1988, p.125). Para Etelvina Trindade, a ocupação de espaços sociais é mais notável exatamente nos momentos de lazer:

o lazer é responsável por uma invasão feminina dos espaços da cidade. Trata-se de um novo domínio, oriundo em grande parte do desenvolvimento urbano, no qual a mulher que a sociedade conservadora oitocentista segregara nas dimensões do privado, retorna às ruas para nelas despender seu tempo livre nas lojas, nos parques, nas casas de espetáculos, nos campos de esportes, nos salões dos clubes recreativos. ${ }^{10}$

Nesse mesmo momento, o remo está se consolidando como o esporte mais popular e simbolicamente valorizado, dividindo o espaço e mesmo superando o turfe nas preferências do público. Essa prática somente se estruturou efetivamente a partir do final da década de 1860, mesmo que as primeiras disputas entre canoas já fossem realizadas desde os anos finais da década de 1840.

Seu desenvolvimento somente se torna possível a partir de uma série de 
modificações na estrutura sociocultural da cidade, em que se destacam o crescimento das preocupações com a higiene e com a saúde, bem como da aceitabilidade de uma nova estética corporal, dimensões diretamente ligadas às iniciativas de modernização da cidade e à paulatina emergência de uma elite com caráter urbano.

Nesse contexto, é luminar a consideração das praias como possibilidade de vivência social, inicialmente compreendidas como estratégia de saúde, depois também encaradas como forma de lazer. Difunde-se o costume dos banhos de mar. Estes tiveram um importante significado para as mulheres, por lhes permitir uma nova oportunidade de convívio social. Segundo Alain Corbin, narrando o que ocorrera na França: "Para as ... condenadas ao lar ... a prescrição médica possibilita uma liberdade inesperada, reserva de sólidos prazeres". ${ }^{11}$

Enquanto isso, para os homens, os banhos de mar ganhavam um sentido diferenciado, ligado aos novos papéis que se começava a esperar que ocupassem, a um novo padrão de masculinidade: "O homem, ao contrário, protagoniza uma cena de coragem; almeja o heró́smo de ter enfrentado as invectivas do mar, de ter sentido na pele o flagelo da água salgada, e de sair vencedor" (Corbin, 1989, p.89).

Vale lembrar como Machado de Assis cita o mar e seus riscos em um de seus romances mais famosos, Dom Casmurro, quando narra uma conversa de Escobar com Bentinho. Afirma o primeiro, para surpresa do segundo: “Tenho entrado com mares maiores, muito maiores. Você não imagina o que é um bom mar em hora bravia. É preciso nadar bem, como eu, e ter estes pulmões, disse ele batendo no peito, e estes braços; apalpa". ${ }^{12}$

Muitas foram as inquietações no que se refere à presença das mulheres nos banhos de mar, ligadas notadamente ao pudor e ao erotismo latente. Assim, não são de se estranhar, tanto na Europa quanto no Brasil, os rigorosos trajes de banho utilizados. Na Europa da década de 1840:

a calça impõe-se às banhistas; a roupa de banho ... compõe-se então de uma camisa e uma calça coladas no corpo e montadas num mesmo molde, de modo a formar um todo contínuo ... As jovens acrescentam um pequeno saiote ajustado à cintura, com a finalidade de dissimular os quadris. Convém não sublinhar demais esse elemento promissor do dote estético. (Corbin, 1989, p.93)

No Brasil dos anos 1860-1880, as mulheres 'de respeito' deveriam tomar banho de madrugada, ainda sem sol, em separado dos homens e usando uma 
indumentária muito pesada e rigorosa. Luiz Edmundo sugere que era constituída de:

calças muito largas de baeta tão áspera que mesmo molhada não lhe pode cingir o corpo. Do mesmo tecido, um blusão com gola larguíssima, à marinheira, obrigada a laço, um laço amplo que serve de enfeite e, ao mesmo tempo, de tapume a uma possível manifestação de qualquer linha capaz de sugerir o feitio vago de um seio. As calças vão até tocar o tornozelo quando não caem num babado largo, cobrindo o peito do pé. Toda a roupa é sempre azul-marinho e encadarçada de branco. Sapatos de lona e corda, amarrado no pé e na perna, à romana. $\mathrm{Na}$ cabeça, vastas toucas de oleado, com franzido à Maria Antonieta, ou exagerados chapelões de aba larga, tornando disformes as cabeças, por uma época em que os cabelos são uma longa, escura e pesada massa. ${ }^{13}$

No Rio de Janeiro do fin de siècle, os banhos de mar já são mais comuns, mesmo para as mulheres. Se ainda persistiam certas restrições, as mais ousadas já não se banhavam tão cedo, o faziam junto com os homens, nas praias chiques e centrais (Boqueirão do Passeio, Glória, Russel, Flamengo) e mesmo já adotavam comportamentos que assustavam a cidade.

Por exemplo, Herminia Adelaide, uma conhecida atriz, escandalizava a população ao banhar-se com roupas coladas ao corpo, desenhando suas belas formas físicas. Usava ainda, para amarrar sua roupa, um cadarço vermelho, um sinal de ousadia naquele momento. Segundo narra Mário Filho, todos paravam para olhar; as moças de família, encabuladas, viravam o rosto para os lados, e os homens, com a cabeça povoada de fantasias, não sabiam bem que atitude tomar. ${ }^{14}$ Alguns anos mais tarde, ao fim da primeira década do século $\mathrm{XX}$, ao contrário disso, fotos de mulheres em seus trajes de banho serão constantemente publicadas nas revistas da moda, tais como O Malho, a Revista da Semana, Fon Fon, o Jornal das Moças.

No contexto de fim de século, não surpreende que a novidade chamasse a atenção do olhar atento e crítico de Arthur Azevedo. Em "Banhos de Mar", ${ }^{15}$ Azevedo narra a história de uma mulher que havia abandonado um namorado jovem que muito amava, por pressão e interesse familiar, para casar com um homem velho e rico. Um problema, contudo, surgira: não conseguia engravidar, o que deixava o marido decepcionado. Procurando um médico, este afirma não ver muitas opções, sugerindo os banhos de mar: 
O médico aduziu, para animá-lo:

— Todavia, Verrier, se não me engano,

Diz que os banhos salgados

Dão belos resultados...

Experimente o oceano!

A citação ao astrônomo e matemático francês Urbain-Jean-Joseph Le Verrier é certamente uma ironia, já que seus estudos nada têm a ver com os banhos de mar: a referência é feita pelo fato de o cientista ter sido um dos responsáveis pela descoberta do planeta Netuno. O que Azevedo fazia era criticar o fato de que os médicos indicavam a prática sem mesmo ter nenhuma certeza acerca de seus benefícios.

Seguindo a recomendação, o casal alugou uma casa de praia e por lá ficou por três meses, até que a senhora engravidou de gêmeos. O velho marido comemora:

— Viva o banho de mar! Ditoso banho!

Dizia, ardendo em júbilo, o marido.

— Eu pedia-lhe um filho, e dois apanho!

Doutor, meu bom doutor, agradecido!

Azevedo segue na crítica à crença exacerbada no aspecto medicinal dos banhos, ao mesmo tempo em que insinua sua relação com o aumento da possibilidade de encontros amorosos. Mais à frente, ficamos sabendo que o antigo namorado alugara uma casa perto do casal, durante a estada na praia, insinuando-se ter ocorrido uma traição: depois que o velho morreu, o jovem casou-se com a viúva e demonstrava amor jamais visto pelos supostos enteados.

A presença feminina nas praias significava mesmo uma grande distensão nos costumes da cidade. E se já existiam diferenças na aceitabilidade de homens e mulheres nos banhos de mar, elas também existiam no que se refere às possibilidades de envolvimento com o remo, esporte que também tem relação com a nova sociabilidade observada no litoral carioca.

Nos anos iniciais do século XX, os remadores serão apresentados como exemplos para a "juventude que vai conduzir o país ao progresso". Vejamos uma representação comum à época, uma referência ao vitorioso remador Arthur Amêndola: "de estatura mediana, moreno, bela complexão de atleta, bastante musculoso, dotado de muito bom gênio e no trato é cortês, excelente companheiro e amigo leal". ${ }^{16}$ 
Sobre uma festa realizada na redação da revista, vemos em uma matéria de A Canoagem o seguinte comentário:

Lá estava o Sardinha, satisfeito, recordando-se ainda de sua vitória na Cecy, o Carlos de Castro, com os braços abertos por causa do muque ... o Guimarães, do Natação, numa exibição impressionadora de peito largo e braços grossos, e outros tantos rapazes sadios e vigorosos, de todos os ramos do sport. ${ }^{17}$

Olavo Bilac, um dos maiores entusiastas do remo, para ele um dos indicadores e contribuintes para o progresso do país, também sacramenta: “As arquibancadas estavam cheias, as carruagens custavam a mover-se e o povo aplaudia, com entusiasmo e alegria, a robustez e a máscula beleza dos bravos rapazes que conduziram ... as suas esbeltas baleeiras". ${ }^{18}$

As baleeiras, os barcos utilizados nas provas, eram considerados pelos remadores quase que como seres vivos, sempre batizados com nomes femininos. Como as mulheres estiveram envolvidas com essa nova configuração do fenômeno esportivo? Somente como nome das embarcações? Certamente que não.

Dentro do novo quadro de participação social das mulheres, onde se percebe mais constantemente sua presença nos momentos de lazer, a prática esportiva ocupa um lugar especial, algo que vinha sendo configurado desde os primórdios do turfe. As regatas eram consideradas ainda mais saudáveis do que as corridas de cavalos, em função de ocorrerem nas praias (um local bastante ligado à modernidade), de sua ligação à idéia de higiene e até mesmo em função dos movimentos dos clubes de remo, que combateram o caráter de jogo de azar ao eliminar as apostas da prática, um claro diferencial no desenvolvimento desse esporte. Isso significa que se ampliaram imediatamente as oportunidades de as mulheres se envolverem como competidoras? Ainda não.

Ana Maria Mauad de S. Andrade ${ }^{19}$ identifica que no Rio de Janeiro da virada do século a mulher e o homem eram fotografados de forma diferenciada. Aos homens se procura representar a partir de uma imagem de ação e poder, figuras, aliás, bem adequadas e características do novo modelo de prática esportiva. Ao observarmos as fotos de remadores, fica clara a nova estética corporal valorizada, onde se procura destacar a masculinidade, a posição de liderança, as idéias de força e prontidão para o desafio. Já as mulheres estavam associadas à família, ao lar e ao lazer como espectadora.

No remo, percebe-se realmente uma pequena participação direta de mulheres. Como dirigentes, algumas sportwoman chegaram a ocupar o cargo de diretoras sociais ou de arquibancadas. Não se tratava dos cargos mais impor- 
tantes dos clubes e regatas, mas há que se ressaltar que, de qualquer forma, um novo passo tinha sido dado. Deve-se destacar que anteriormente sequer existia um termo pra designar as mulheres envolvidas com o esporte, como o sportman, utilizado para designar os aficionados masculinos. Se um novo termo chega aos jornais e revistas, isso pode ser um indicador de que havia uma nova sensibilidade acerca dos papéis femininos.

Além disso, em nossas investigações foi possível identificar algumas iniciativas de participação de mulheres como remadoras, duas dessas na década de 1880: três francesas remavam não competitivamente em Niterói (senhoritas Massiere, Tribouillet e Vianna), enquanto algumas inglesas faziam o mesmo em São Cristóvão (irmãs Fox).

Ressalta-se a origem de algumas das envolvidas: de família estrangeira (de países nos quais, ainda que embrionariamente, as mulheres já se envolviam com o esporte), e/ou pertencentes às elites. O pai da senhorita Massiere era um armador francês, no Brasil um dos pioneiros da construção de embarcações para a prática do remo, prática pela qual era apaixonado. Quanto à senhorita Vianna, não temos como categoricamente afirmar, mas muitos indícios apontam que seja da família do notório jurista brasileiro Francisco José de Oliveira Vianna, que esteve envolvido com o desenvolver de uma estrutura jurídica para o remo. Até o momento não encontramos maiores informações sobre Tribouillet e as irmãs Fox, a não ser o fato de que são de famílias oriundas de outros países.

A terceira iniciativa é a criação, em 1901, do Grupo de Regatas Feminino da Ilha de Pombeba (pequena ilha localizada na baía de Guanabara, em frente à antiga praia de São Cristóvão). Sua diretoria era formada por: Silvia Peixoto (presidente), Gabriela Filgueiras (vice-presidente), Elisa Joppert (secretária) e Alice Ferreira (tesoureira).

Esse grupo não sobreviveu muito tempo: disputou apenas uma prova contra remadoras do Grupo de Regatas Cajuense, agremiação que logo mudaria de nome para Clube de Regatas São Cristóvão (que em 1943 se fundiu com o São Cristóvão Atlético Clube, dando origem ao atual São Cristóvão Futebol e Regatas).

Próximo do recorte temporal de nosso estudo, identificamos ainda um páreo feminino (que foi denominado prova de honra "Sra. Josephina Azurem Furtado"), ${ }^{20}$ realizado em regata promovida, em 15 de outubro de 1911, pelo Clube de Regatas Boqueirão do Passeio. A guarnição do São Cristóvão venceu com uma guarnição composta por Antenor "Anão" de Andrade (patrão; 
já que não remava, era aceito nessa função um homem), Noêmia Batista e Sílvia Sá (remadoras).

Ainda que não tenha encontrado outros indícios, não descarto a possibilidade de que outras mulheres tenham praticado o remo, especialmente como opção de lazer. O que parece, a partir dos dados coletados, é que não era comum a existência de remadoras: as provas realizadas, a exemplo do que ocorrera com o turfe, eram esporádicas.

O que estaria por trás da não continuidade das atividades do grupo feminino de remo e da não realização de um número maior de provas femininas? Certamente havia estranhamentos de ordem moral: se a participação dos homens nas regatas, a despeito do clima favorável nos primeiros anos do século XX, ainda chamava a atenção e causava polêmicas, pelas roupas 'muito curtas' e pela 'excessiva' exposição corporal para os padrões da época, supomos que para as mulheres esses aspectos deveriam ser ainda mais elementos complicadores.

A cidade já convivia com personagens cuja performance pública era impensável alguns anos antes, tais como Laurinda Santos Lobo, Bebê Lima de Castro, Chiquinha Gonzaga, Maria de Melo, a já citada Hermínia Adelaide. Essas, contudo, sem deixar de reconhecer seu importante papel, ligavam-se mais à arte e desfilavam pelos salões com belas vestimentas, não 'sem roupas', como era o caso do remo.

Devemos considerar ainda que mesmo no cenário internacional o remo feminino ainda demoraria a se consolidar. Para que tenhamos uma noção clara, basta dizer que somente em 1969 se criou uma comissão feminina na Federação Internacional de Remo, tendo em vista garantir uma maior participação das mulheres nas regatas. O primeiro campeonato mundial só foi disputado em 1974 e sua presença nos Jogos Olímpicos só pôde ser observada em Montreal, em 1976. Somente em 1980 a tradicional norte-americana National Association of Amateur Oarsmen, criada em 1872, muda de nome já que cerca de um terço dos afiliados eram mulheres.

No Rio de Janeiro, já na década de 1950, houve algumas tentativas de implementar o remo feminino, com a realização de provas nos Jogos da Primavera. Contudo, o fato de algumas remadoras terem chegado exaustas em alguns páreos (fato que também ocorrera com os homens, sem ser motivo, todavia, de grandes observações) desencadeou críticas e levou a Confederação Brasileira de Desportos a proibir tais provas. Somente em 1984 foi realizado o I Campeonato Brasileiro Feminino de Remo. ${ }^{21}$

Se durante muitos anos persistiram dúvidas sobre a adequação de mu- 
lheres praticarem atividades físicas, notadamente as intensas como é o caso do remo, isso não significou desvalorização da participação feminina nas regatas na virada para o século XX. Como lembra Needell:

Além da administração doméstica, as mulheres eram as estrelas no palco da alta sociedade. Pois a exibição de roupas e jóias, o comportamento no salão e nos chás, e a graça que conferiam às recepções semanais serviam como indicadores confiáveis do status familiar. Todas as atividades da alta sociedade requeriam necessariamente a presença das mulheres. (Needell, 1993, p.159)

Era de grande importância garantir o 'caráter familiar' da prática, pois se o novo contexto sociocultural do início do século XX permitia e até estimulava uma maior exposição pública, o papel da família, ainda que alterado, continuava a ser de grande importância. Rosa Maria Barboza de Araújo lembra que esse processo acabou por gerar mudanças nos papéis sociais: "A intensidade e rapidez das transformações urbanas na virada do século XX deu novo impulso à dinâmica familiar, neutralizando a supremacia do poder masculino, diversificando as formas de socialização da mulher" (Araújo, 1993, p.58).

Nas notícias sobre as regatas e atividades dos clubes de remo, publicadas nos jornais e revistas da época, a presença de mulheres nas arquibancadas era constantemente exaltada, notadamente as jovens que 'enfeitavam' o ambiente: para elas concebia-se o papel de torcedoras saudáveis e atentas aos novos tempos. Vejamos alguns exemplos em A Canoagem:

Desde 10 horas que começaram a chegar os convidados e entre eles aquelas caravanas de peregrinas jovens, trajando vestes alegres, quais sorrisos infantis das alvoradas de agosto ... Era enorme o número de senhoritas, de toilettes claras e elegantes...22

Incontestavelmente a festa foi magnífica, entre as belezas daquele verdadeiro templo podemos destacar os nomes daquelas almas jovens e sadias que deram maior entusiasmo à festa. ${ }^{23}$

As arquibancadas ficaram repletas de convidadas e com um belo aspecto devido às variadas cores das toilettes das gentis senhoritas que iam dar o tom alegre a esta festa esportiva. ${ }^{24}$

É interessante notar que em várias capas desse periódico já há ilustrações de mulheres em trajes esportivos, dividindo o espaço com os homens nas re- 
ferências aos clubes ( 9 de setembro de 1903) e mesmo cercada de implementos como um remo, uma espada e um chicote ( 8 de agosto de 1903). Mesmo que ainda mais idealizado do que concreto, um novo perfil 'esportivizado' de mulher começa a obter mais espaço, vai penetrando e abrindo espaço por entre as frestas sociais.

Assim como no turfe, as competições de remo eram também espaços de flerte. Na realidade, em função da nova sociabilidade pública, dos novos papéis sociais possíveis para homens e mulheres, a possibilidade de encontros amorosos era até mesmo mais forte nas regatas: os jovens as tinham como espaço para desfilar sua forma física para as 'senhoritas'. Com isso, persistiam as preocupações com o pudor.

Em "A filha do patrão", ${ }^{25}$ Arthur Azevedo nos dá uma mostra de tais contatos. O autor narra a história de um pai que ficou indignado com um jovem que pedira sua filha em casamento. Segue-se uma parte do diálogo entre pai e filha:

— Quem é aquele pelintra?

- Chama-se Borges.

— De onde o conhece você?

— Do Clube Guanabarense... ${ }^{26}$ Daquela noite em que papai me levou...

— Ele em que se emprega? Que faz ele?

- Faz versos.

— E você não tem vergonha de gostar de um homem que faz versos?

Vale citar ainda a referência irônica de Arthur Azevedo na opereta Os Noivos (1880). ${ }^{27}$ Diz D. Maria, uma das personagens:

— Pois será possível que eu não ache marido? Eu que tenho quarenta apólices da dívida pública e uma casa assobradada na vila, afora o que ainda pode vir de minha irmã das Laranjeiras? ... Não hei de faltar aos bailes, espetáculos, concertos, touradas, corridas e regatas! Regatas, então! Não sei o que é, nunca vi, mas parece-me que hei de ser muito regateira!

A despeito da mudança de quadro, temos que tomar cuidado ao considerar os avanços. Tratava-se sim de conquista de espaços pelas mulheres, mas também de uma liberdade controlada e concedida: "Pois a alta sociedade por mais feminina que fosse em sua expressão, era masculina em seu propósito. 
Ela servia para manter e promover os interesses das famílias da elite, definidos pelos pais e maridos que os supervisionavam" (Needell, 1993, p.160).

Needell (1993) chama a atenção para que não se confunda um maior mundanismo com liberação completa. Para ele, a ampliação da possibilidade de participação social feminina estava também inserida no contexto das necessidades dos homens dos 'novos tempos'. Além disso, se a rápida urbanização interferia na reformulação dos papéis femininos, as mentalidades não mudariam tão rapidamente. Durante muito tempo ainda estaria associada às mulheres uma idéia de beleza frágil, fundamentalmente situada na aparência e no vestuário.

Não surpreende, assim, que estivessem afastadas do remo enquanto atletas, já que ao redor dessa prática se construíra uma visão antagônica aos papéis delas esperados. Contudo, na década final do século XIX e na inicial do $\mathrm{XX}$, outras práticas esportivas já estavam se configurando na cidade e em todas elas se podia identificar alguma participação feminina, com distintas formas de envolvimento, em função das diferentes representações que cercavam cada uma das modalidades.

\section{OUTROS ESPORTES, OUTRAS CONFIGURAÇÕES ${ }^{28}$}

Comecemos pelas modalidades nas quais se podia perceber uma participação feminina mais direta. Com peculiaridades, esse é o caso da esgrima, do hipismo, do tiro ao alvo, do atletismo e do cricket. No caso das três primeiras, a aceitação das mulheres como praticantes estava relacionada ao fato de que eram concebidas como parte da educação das moças das elites, consideradas importantes em função de que deveriam desenvolver certas habilidades que lhes permitissem desempenhar bem os novos papéis sociais delas esperados. Além disso, eram encaradas como sinais de status e distinção, marcas de classe social.

A esgrima é praticada no Brasil desde os primeiros anos do século XIX, tanto nas escolas militares quanto nas escolas das elites que possuíam ensino padrão, já entendida como importante elemento de formação masculina. Era também oferecida em aulas particulares, normalmente por instrutores estrangeiros. A partir da década de 1860, começa a também ser ensinada em agremiações esportivas, como no Clube Ginástico Português, fundado em 1868, ativo até os dias de hoje. É nesses espaços que as mulheres começam a praticá-la.

É somente nos anos finais do século XIX que começa a se estruturar um 
calendário de competições de esgrima, que nunca alcançaram grande popularidade. No caso desses torneios, às mulheres eram reservadas as arquibancadas: a elas era permitida a prática em espaços privados, mas não em disputas públicas.

O hipismo era também praticado na cidade desde a primeira metade do século XIX. No início do século XX, o Rio de Janeiro já possuía três centros hípicos e muitas competições eram organizadas, mas também estas não gozavam de grande popularidade. Nessa modalidade, as mulheres já tomavam parte ativa nas provas. Vale destacar que a equitação é um dos únicos esportes atuais em que não há divisão entre categorias masculinas e femininas: os atletas competem em grau de igualdade na mesma prova.

O tiro ao alvo surge como prática esportiva na região sul do país. No Rio de Janeiro, existia desde a década de 1830, mas relacionado à prática da caça. Nas primeiras décadas do século XX já eram organizadas provas, normalmente exclusivas para as mulheres, na mesma ocasião de competições de outras modalidades, especialmente do ciclismo.

As fotos dessas mulheres eram constantemente divulgadas nas principais revistas da cidade, quando se denotava o 'charme' e a 'vestimenta' das praticantes. Um interessante indicador das representações da prática feminina do tiro pode ser encontrado em O Malho de 28 de abril de 1906. Ao comentar a realização de provas em Petrópolis, o periódico comenta a atuação das "peritas atiradoras" e afirma que o desenvolvimento desse "sport feminino" era valioso para a defesa da pátria e do lar.

Em três outras modalidades, a participação feminina estava ligada a questões culturais: "jogos atléticos" e "corridas a pé" (primórdios do atletismo) e o cricket foram implementados basicamente por clubes de ingleses que, seguindo os costumes de seu país, já concebiam mais facilmente o envolvimento de mulheres como atletas, desde que em provas 'mais leves', sempre com a preocupação de não ferir sua feminilidade. Deve-se destacar que as roupas usadas em nada lembravam os trajes esportivos atuais: eram basicamente uma versão pouco mais descontraída da pesada vestimenta cotidiana.

Um clube importante para o desenvolvimento desses esportes foi o Rio Cricket Club, criado em Botafogo, em 1872, e instalado, em 1880, em um campo da rua Paissandu. Desde o início ficou estabelecido que, além do campo de cricket, seriam construídas uma pista de corridas e instalações para a prática de saltos e lançamentos. O estilo de vida inglês implementado por essa agremiação atraía uma parte das elites cariocas, inclusive a família real, nota- 
damente a princesa Isabel e o conde D'Eu, que moravam praticamente em frente.

Ainda que não popular, o clube tem sua importância no propagar dos benefícios da prática esportiva, por constantemente ceder instalações e apoiar as realizações de outros esportes (como o futebol, nos primeiros anos do século XX), por referendar um sentido 'europeu' de clube e por sempre abrir as possibilidades para que as mulheres atuassem como competidoras.

Em outras modalidades as restrições eram maiores, semelhantes ao que se observava no já discutido caso do remo: nas competições de natação e de ciclismo, a presença feminina era aceita e valorizada nas arquibancadas, mas não diretamente nas provas. A nossa hipótese é que pesavam tanto o grau de movimentação e exposição corpórea necessário às práticas quanto o caráter bastante popular desses esportes.

As primeiras preocupações com o ensino e a prática da natação surgem com a popularização dos banhos de mar, tendo em vista a segurança dos banhistas. A natação também estava ligada a um novo estilo de vida mais saudável, em que se preconizava um contato mais íntimo com a natureza. Já no final do século XIX, alguns colégios da elite construíram tanques para a prática e a Livraria Laemmert, uma das mais importantes da cidade, traduziu do francês o Manual da arte de nadar.

Aproximadamente nessa época começaram a ser organizadas travessias da baía de Guanabara. Em 1896, surge o Clube de Natação (mais tarde Natação e Regatas), que organizaria, já nesse ano, uma competição bem estruturada de seis páreos. Em 1898, a agremiação promove a primeira edição do Campeonato Brasileiro de Natação: uma única prova de 1.500 metros, sem estilo definido, para homens, realizada entre o Forte de Villegaignon e a praia de Santa Luzia.

É somente na década de 1920 que piscinas começaram a ser construídas no Brasil, pioneiramente na cidade de São Paulo. É também a partir desse momento que se observa o início de uma participação mais freqüente de nadadoras, onde se destacam os nomes de Blanche Pironnet, Anésia Coelho, Alice Possolo, Maria Lenk, Helena Salles e Piedade Coutinho, entre outras.

O caso do ciclismo merece uma atenção especial, pelo simbolismo do esporte no fin de siècle. Como demonstram Schetino e Melo, ${ }^{29}$ a bicicleta ocupara um importante espaço na Paris do século XIX, saudada pelas mulheres como um aparato que estimulava sua maior presença social e suas lutas por liberdade. É possível identificar influências desse quadro no cenário nacional.

$\mathrm{O}$ uso das bicicletas pelas mulheres era observado como prática de lazer 
não competitiva, somente possível para as ligadas à elite, já que eram altos os custos de um 'velocípede'. A prática do ciclismo, ainda que expressasse as mudanças dos papéis sociais, estava também relacionada à valorização de vestimentas elegantes, a uma forma de expressão da beleza, elegância e delicadeza: não deveria ferir os 'valores femininos', algo bastante distinto das idéias exaltadas pela prática de competição: força, agilidade, velocidade. ${ }^{30}$

Não foi possível identificar a realização de provas femininas, à exceção de alguns páreos para crianças, organizados de forma esparsa, geralmente na ocasião de celebrações especiais. Aliás, mesmo a prática de lazer provocava apreensão. É o que demonstrava Bambino, em suas "Notas Semanais”, publicadas no Jornal do Brasil de 21 de janeiro de 1900. A charge, intitulada "Conseqüências Naturais”, retrata dois cavalheiros bem vestidos olhando com expressão jocosa para algumas mulheres ciclistas.

De qualquer maneira, os jornais e revistas noticiavam constantemente a presença das mulheres nos velódromos por ocasião das competições. Vejamos um exemplo: "Com um bonito dia, realizaram-se as grandes corridas do Velo Club, cujo aspecto era belíssimo, já pelo gosto da decoração, já pela afluência de toilettes chiques com que se apresentavam as inúmeras senhoritas que lá estavam". 31

Enfim, a heterogeneidade do grau de participação e presença feminina expressa bem a complexidade do envolvimento das mulheres com o campo esportivo no Brasil, algo que é também expressão das tensões na construção de novos papéis sociais em todos os âmbitos da cidade naquele instante.

\section{LUTA ROMANA: UM CASO PECULIAR}

Nos anos finais do século XIX, foi comum em muitos países, com destaque para os Estados Unidos, a organização de espetáculos em que homens exibiam sua forma física, por meio de números de força, acrobacias e lutas diversas. Esses shows têm raízes muito anteriores, sendo possível observar análogos na Antiguidade, no período medieval e mesmo nos anos iniciais do referido século, até mesmo na cidade do Rio de Janeiro. ${ }^{32}$

Na transição dos séculos XIX e XX, contudo, esses espetáculos ganham um formato específico, articulados com a idéia de valorização do entretenimento, de exaltação da ciência e de crescimento da curiosidade pelo corpo, no mesmo contexto em que são muito procurados pelo público os circos dos 
horrores, os museus de cera, as lutas de boxe, entre outros (inclusive o cinema e o esporte), atividades em que a exposição corpórea ganhava destaque. ${ }^{33}$

Ainda que pairassem dúvidas, por razões médicas e morais, sobre a adequação do excesso de exercício e da hipertrofia muscular, entre a população esses eventos de exibição eram muito apreciados, estabelecendo-se uma clara tensão entre as preocupações 'oficiais' e aquilo que popularmente era valorizado.

Jan e Terry Todd ${ }^{34}$ demonstram que nesses espetáculos eram comuns apresentações de mulheres fortes, cujo impacto e poder de atração se encontravam no próprio fato de apresentarem uma postura e um modelo corporal diametralmente oposto ao que era majoritariamente aceito. Entre muitas outras que ganhavam a vida, assustavam e encantavam o público com suas performances, podemos citar as norte-americanas Josephine Schauer (conhecida como Minerva) e Belle Gordon, a belga "Athleta”, a austríaca Katie Brumbach, apelidada de "Sandwina", uma referência a Eugene Sandow, reconhecido pelo seu porte físico e por desenvolver um método de treinamento físico.

Jan Todd ${ }^{35}$ argumenta que havia uma grande fascinação por essas personagens, que mesclavam força, feminilidade e independência pessoal. De alguma forma isso era tanto um indício quanto um contributo para a construção de novos papéis sociais femininos, a despeito das polêmicas que as cercavam. Na realidade, é possível perceber, sem desprezar a força da construção narrativa, que um determinado modelo ideal de mulher se prendia mais notavelmente à concepção de uma determinada classe social, que, ainda que tivesse influência no cômputo geral da população, não se impunha de forma linear por todos os estratos.

No Rio de Janeiro, no período estudado, encontramos um episódio de realização de lutas de mulheres. No início do século XX, no Brasil começou a se tornar mais comum a prática da luta romana, notadamente desafios entre atletas cariocas e de São Paulo. José Floriano Peixoto foi um dos mais renomados dessa modalidade naquele momento, praticamente o nosso Sandow.

No seu livro de memórias, comenta Luiz Edmundo, captando bem o momento de transição:

Não se pratica a ginástica do corpo. A do sentimento basta. E nesse particular, ninguém supera o jovem desse tempo ... Vive ainda da lírica do poeta Casimiro de Abreu, acha lindo sofrer-do-peito, bebe absinto e, de melenas caídas nas orelhas, ainda insiste em recitar ao piano. Toda uma plêiade de moços de olheiras profundas, magrinhos, escurinhos, pequeninhos ... Tipos como o do atleta José Floriano Peixoto, são olhados, por todos, com espanto. (Edmundo, 1957, p.833) 
Zeca Peixoto, como era conhecido, destacava-se não só pelo seu corpo forte, como também pelo fato de ser praticante e campeão de muitos esportes diferentes. Ganhou ar de herói quando salvou diversas pessoas em um naufrágio que ocorrera na Bahia, ocasião em que retornava de excursão à Europa.

Nos primeiros anos da década de 1900, Peixoto já estava envolvido com o grupo de Paul Pons, um francês muito atuante nos primeiros momentos do halterofilismo no Brasil e no mundo. No decorrer da década esteve envolvido com apresentações em teatros, fazendo parte da "Companhia Ginástica e de Variedades" e chegando a ser proprietário de um circo (Circo Floriano), que fez sucesso na cidade.

Peixoto, junto com o empresário paulista Francisco Serrador, estava por trás da organização de um campeonato de lutadoras, realizado no Teatro São Pedro de Alcântara, no ano de 1910. Tratava-se, na realidade, de uma temporada teatral, em conjunto com o grupo musical feminino Mirales; as lutas eram realizadas entre estrangeiras, com a participação de algumas brasileiras que vieram de São Paulo.

O evento teve grande repercussão na cidade. A revista Fon-Fon de 7 de maio de 1910 publica, sob o título "O muque feminino", uma foto das competidoras, em trajes de luta (com braços e pernas descobertas), em posições que lembravam muito a dos atletas masculinos; ao centro, em trajes aristocráticos, o árbitro das pelejas.

Na edição de 28 de maio de 1910, a revista publica novas imagens, espalhadas pelas páginas, sempre sob o título "As lutadoras", informando o nome de algumas competidoras: a russa Schuwalod, Nero Berkson (que foi alcunhada de Minas Gerais, nome do navio adquirido pela Marinha brasileira à época), Philippi, Morgan, Nelson, Fisher, Rieb e Schmidt. Na edição de 4 de junho ficamos sabendo o nome das brasileiras: Annita e Nenê.

Interessante observar que essas fotos não seguem o modelo da edição de 7 de maio de 1910, mas sim a tradicional forma de representação das mulheres na revista: trajes elegantes, plenamente adequados à moda. Aparentemente, o periódico indicava que, ainda que lutadoras, tratava-se de mulheres como as outras.

Essa impressão fica mais forte quando vemos que no mesmo número foi publicada uma foto, sob o título "O muque masculino" (o oposto da foto das mulheres publicada na edição de 7 de maio), onde posam atletas do Centro de Cultura Física Eneas Campelo, um dos pioneiros na cidade, situado à rua das Marrecas (Centro). A postura é a já tradicional naquele momento no que 
se refere aos esportistas: sem camisa, exibição dos músculos, posturas másculas; na parede da academia se vê escrito: "o homem forte é sensato e calmo".

O espetáculo das mulheres parece ter tido grande sucesso. $\mathrm{O}$ editorial da Fon Fon de 28 de maio, além de apresentar sutis desculpas para algumas dimensões que deveriam chocar o público (as roupas curtas, a forma física das lutadoras), exalta:

A luta romana por mulheres tem mais encanto que por homens. O maillot completo que as lutadoras vestem (e não podiam deixar de vestir) dá-lhes uma certa elegância flexível que destaca mais a estética do gesto e do movimento. A Minas Gerais lutando interessa mais, apesar da fortuna de banhas, do que toda escola sabida de Paulo Pons. Para minha ignorância esportiva, chega mesmo a parecer que elas lutam melhor do que eles.

A Revista da Semana também noticiou com fervor o evento. Na edição de 22 de maio de 1910, publica uma foto da russa Schuwalod, em plena pose de um dos golpes da luta. A matéria informa que, pela excelente performance, fora apelida pela platéia de Menina de Ouro. Além disso, comenta:

O teatro regorgita. Dois atrativos de primeira ordem no gênero, a troupe feminina musical Mirales, que executa primorosos trechos musicais, e a luta romana de mulheres sacudidas e fortes que se pegam a valer, provocando grande entusiasmo. Bastam esses dois números para que o teatro se encha todas as noites.

Houve certamente estranhamentos. As roupas e posturas das competidoras chamavam a atenção e eram motivo de críticas (mesmo que os periódicos tentassem apresentá-las como mulheres 'normais'). Os mais ligados ao campo esportivo criticavam o formato de realização, como podemos ver na Revista da Semana de 29 de maio de 1910, na coluna "Sport": "Somos dos que não tem muita fé nos campeonatos organizados com fins mercantis. As lutas no São Pedro, porém, transcorreram sob um cunho inesperado de seriedade".

Algumas notícias ainda permitem vislumbrar certos desconfortos, como a publicada na Fon Fon de 21 de maio de 1910, comentando que o conhecido J. J. Seabra comparecera ao espetáculo: "Não queira convencer-me de que S. Ex. ali foi por um simples movimento de curiosidade ... Não engulo. Mesmo porque uma luta romana de mulher não é lá, para que digamos, um espetáculo muito decente para um líder”.

Certamente a realização desse certame constitui uma exceção à época. 
Vale, todavia, comentar que a grande divulgação, o sucesso da empreitada, o fato de ser notícia em importantes periódicos, o tempo em que foi motivo de curiosidade são indicadores de uma nova sensibilidade sendo gestada. Se persistiam as dúvidas quanto à adequação moral e física da prática (mais a primeira do que a segunda), a dimensão de espetáculo vai impulsionar cada vez mais a presença ativa de mulheres no âmbito esportivo.

\section{CONSIDERAÇÕES FINAIS}

Na coluna "Sport" do Jornal do Brasil de 15 de dezembro de 1894 podemos encontrar os comentários anônimos de uma senhora acerca dos esportes na cidade. Segundo ela, era agradável ir aos hipódromos, apreciar o comportamento dos freqüentadores; os divertimentos do turfe eram fundamentais para fazer esquecer os aborrecimentos do cotidiano. Para ela, as "pugnas sportivas" são ocasiões em que "a inteligência e a força do homem correm parelhas" (p.7). Diversões como o ciclismo, difícil de praticar em função da necessidade de equilíbrio, ressalta a autora, desenvolvem até mesmo a musculatura.

Ao analisarmos as revistas e os jornais cariocas da transição para o século XX, cada vez mais veremos a presença de mulheres envolvidas com práticas esportivas. Isso de alguma forma atende a alguns interesses masculinos, destacando-se sua inserção em um mercado de consumo que se ampliava ao redor do esporte. Ao mesmo tempo não se pode negar que também foi fruto de suas reivindicações e significava uma conquista. Era um indicador de libertação, uma abertura de novas possibilidades, um avanço, uma preparação para conquistas maiores.

Vencendo resistências, nesse percurso inicial semearam-se as condições de ampliação futura de seu envolvimento com o campo esportivo. Em $1^{\circ}$ de janeiro de 1913, uma matéria publicada no Jornal do Brasil, denominada "O que serão as moças em 1913”, já situa o esporte entre as mais claras mudanças no comportamento feminino. Segundo a matéria, a prática de algumas modalidades poderia mesmo "aperfeiçoar as suas belezas físicas, apurandolhes as linhas esbeltas e vigorosas” (p.8).

No decorrer do século XX, paulatinamente cada vez mais as mulheres tomaram parte ativa no espetáculo esportivo, como público, como atletas e como dirigentes (neste caso, em menor número). Nos dias de hoje, já ocupam posições antes tidas como exclusivamente masculinas, como treinadoras e árbitros. 
Ainda assim, apenas recentemente duas mulheres conquistaram pela primeira vez medalhas de ouro em Jogos Olímpicos: Jacqueline Silva e Sandra Pires, dupla feminina de vôlei de praia (Atlanta, 1996). Somente nos Jogos de Atenas (2004), quando o Brasil contou com sua maior delegação feminina, o número de atletas mulheres se aproximou da delegação masculina. E como vimos, ainda permanecem muitas diferenças.

Mais de 100 anos depois das suas primeiras participações como atletas, nas experiências pioneiras do turfe e do remo, no esporte, como na sociedade em geral, as mulheres seguem na busca de condições, de oportunidades e de espaços similares aos dos homens.

\section{NOTAS}

${ }^{1}$ Estou trabalhando com o conceito de esporte moderno/campo esportivo de Pierre Bourdieu. Maiores informações em: BOURDIEU, Pierre. “Como é possível ser esportivo?”. In: BOURDIEU, Pierre. Questões de sociologia. Rio de Janeiro: Marco Zero, 1983. p.136-153. Para maiores informações sobre os primórdios do esporte no Rio de Janeiro, ver: MELO, Victor Andrade de. Cidade "Sportiva". Rio de Janeiro: Relume Dumará/Faperj, 2001.

${ }^{2}$ Apud SILVA, Maria Beatriz Nizza da. Cultura e sociedade no Rio de Janeiro - 1808/1821. São Paulo: Cia. Ed. Nacional, 1978. p.103.

${ }^{3}$ Para maiores informações, ver: WEBER, Eugen. França fin de siecle. São Paulo: Companhia das Letras, 1988.

${ }^{4}$ PACHECO, Eduardo. Crônicas do turf fluminense. Rio de Janeiro: s.n., 1893. p.6.

${ }^{5}$ BILAC, Olavo. As corridas. In: COSTA, Nélson. Páginas cariocas. Guanabara: Secretaria Geral de Educação e Cultura, 1961. p.280.

${ }^{6}$ In: COSTA, Flávio Moreira da (Org.). Arthur Azevedo - "Plebiscito" e outros contos de humor. Rio de Janeiro: Revan, 1993. p.87.

${ }^{7}$ Para maiores informações sobre os clubes, ver: NEEDELL, Jeffrey D. Belle époque tropical. São Paulo: Companhia das Letras, 1993.

${ }^{8}$ Os conflitos entre os clubes são uma expressão das tensões entre dois setores das elites: um urbano, mais empresarial (reunido ao redor do Derby e que posteriormente, junto com profissionais liberais, vai dar origem ao remo carioca) e outro mais tradicional, ligado ao capital agrário (reunido em torno do Jóquei Clube). Mais informações em estudo de Melo (2001).

${ }^{9}$ Maiores informações em: ARAÚJO, Rosa Maria Barboza de. A vocação do prazer: a cidade e a família no Rio de Janeiro republicano. Rio de Janeiro: Rocco, 1993. 
${ }^{10}$ TRINDADE, Etelvina. Cidade moderna e espaços femininos. Projeto História, São Paulo, n.13, p.109-120, jun. 1996. p.112.

${ }^{11}$ CORBIN, Alain. O território do vazio: a praia e o imaginário ocidental. São Paulo: Companhia das Letras, 1989. p.88.

${ }^{12}$ ASSIS, Machado de. Dom Casmurro. São Paulo: Klick, 1997. p.57.

${ }^{13}$ EDMUNDO, Luiz. O Rio de Janeiro do meu tempo. Rio de Janeiro: Conquista, 1957. p.838. ${ }^{14}$ RODRIGUES FILHO, Mário. Histórias do Flamengo. Rio de Janeiro: Irmãos Pongetti Ed., 1945.

${ }^{15}$ In: COSTA, Flávio Moreira da (Org.), cit, 1993, p.105-110.

${ }^{16}$ SEÇÃO não official. A Canoagem, Rio de Janeiro, ano 1, n.17, p.4, out. 1903. p.4.

${ }^{17}$ A Canoagem, ano 1, n.2, p.5-6, 11 jul. 1903.p.5.

${ }^{18}$ X. A cidade. A Canoagem, Rio de Janeiro, ano 1, n.1, p.5, jul. 1903. p.5. O pseudônimo X. era utilizado por Bilac.

${ }^{19}$ ANDRADE, Ana Maria Mauad de S. Sob o signo da imagem: a burguesia carioca de 19001950. À margem, Niterói, ano 1, n.1, p.5-14, 1993.

${ }^{20}$ Josephina era esposa de Júlio Furtado, durante muitos anos Inspetor de matas e jardins da prefeitura, grande incentivador do esporte e membro honorário da Federação Brasileira de Sociedades de Remo.

${ }^{21}$ LICHT, Henrique. O remo através dos tempos. Porto Alegre: Corag, 1986.

${ }^{22}$ A Canoagem, Rio de Janeiro, ano 1, n.7, p.1-7, ago. 1903. p.6.

${ }^{23}$ A Canoagem, Rio de Janeiro, ano 1, n.12, p.3, nov. 1903. p.3.

${ }^{24}$ A Canoagem, Rio de Janeiro, ano 1, n.16, p.3, out. 1903. p.3.

${ }^{25}$ Essa obra pode ser encontrada na íntegra na página do Núcleo de Pesquisas em Informática, Literatura e Lingüística: www.nupill.org/.

${ }^{26}$ Esse clube é um dos pioneiros e mais importantes no que se refere à prática do remo no Rio de Janeiro.

${ }^{27}$ Essa obra pode ser encontrada na íntegra na página do Núcleo de Pesquisas em Informática, Literatura e Lingüística: www.nupill.org/.

${ }^{28}$ Além das que vamos comentar neste artigo, havia ainda a presença de mulheres na patinação, no golfe, no tênis e mesmo no automobilismo.

${ }^{29}$ MELO, Victor Andrade de; SCHETINO, André. O esporte, a bicicleta e as mulheres no Rio de Janeiro da transição dos séculos XIX e XX. Rio de Janeiro: 2007. mimeo.

${ }^{30}$ Para maiores informações sobre o ciclismo, ver: SCHETINO, André. Pedalando na modernidade: a bicicleta e o ciclismo em Paris e no Rio de Janeiro na transição dos séculos 
XIX e XX. Dissertação (Mestrado em História Comparada) - IFCS/UFRJ, Rio de Janeiro, 2007.

${ }^{31}$ A Canoagem, Rio de Janeiro, ano 1, n.4, 25 jul. 1903. p.9.

${ }^{32}$ MELO, Victor Andrade de. Dicionário do Esporte no Brasil. Campinas: Autores Associados, 2007.

${ }^{33}$ Para mais informações, ver: SCHWARTZ, Vanessa R. O espectador cinematográfico antes do aparato do cinema: o gosto do público pela realidade na Paris fim-de-século. In: CHARNEY, Leo; SCHWARTZ, Vanessa (Org.). O cinema e a invenção da vida moderna. São Paulo: Cosac \& Naify, 2001; e VIEIRA, João Luiz. Anatomias do visível: cinema, corpo e a máquina da ficção científica. In: NOVAES, Adauto (Org.). O homem-máquina: a ciência manipula o corpo. São Paulo: Companhia das Letras, 2003; MELO, Victor Andrade de. Cinema e esporte: diálogos. Rio de Janeiro: Aeroplano/Faperj, 2006.

${ }^{34}$ TODD, Jan; TODD, Terry. A legacy of strength: the cultural phenomenon of the professional strongwoman. North American Society for Sport History. Proceedings and newsletter, 1987, p.13-14.

${ }^{35}$ TODD, Jan. Entertainers or athletes? Professional strongwomen, vaudeville and the earlytwentieth-century fascination with female strength. North American Society for Sport History. Proceedings and newsletter, 1996, p.13; TODD, Jan. The strong lady in America: professional athletes and the Police Gazette. North American Society for Sport History. Proceedings and newsletter, 1990, p.98-99.

Artigo recebido em novembro de 2007. Aprovado em dezembro de 2007. 